\title{
Radiation Enhancement with Polyethyleneimine-Coated Gold Nanoparticles Under MV Photons
}

\author{
(1) Süheyla AYTAÇ ARSLAN, ${ }^{1}$ (I) Mustafa TÜRK² \\ 'Department of Radiation Oncology, Ankara Ataturk Research and Training Hospital, Yildirim Beyazit University School of Medicine, \\ Ankara-Turkey \\ ${ }^{2}$ Department of Bio-Engineering, Faculty of Engineering, Kırıkkale University, Kırıkkale-Turkey
}

\begin{abstract}
OBJECTIVE
Radiotherapy is an essential part of cancer management, and about two-thirds of the patients with cancer receive radiation therapy during their treatment. The healthy structures around the tumor are dose limiting in terms of acute and late toxicity. Radiosensitizers (RSs) can be used to enhance intratumoral dose, thus improving the therapeutic ratio. We aimed to investigate the cytotoxicity on normal and cancer cell lines induced by interaction between MV photon irradiation and polyethyleneimine (PEI)coated gold nanoparticles (AuNPs).
\end{abstract}

\section{METHODS}

The effects of different concentrations of AuNPs $(0.75 \mu \mathrm{g} / \mathrm{ml}, 0.5 \mu \mathrm{g} / \mathrm{ml}, 0.25 \mu \mathrm{g} / \mathrm{ml}$, and only medium) and 2 Gy ionizing radiation (IR) were investigated on the L929 fibroblast, DLD-1 colon, and H1299 lung cancer cell lines. Cytoplasmic and nuclear membranes treated with hematoxylin and eosin and double staining were evaluated with light and fluorescence microscopy. Cytotoxicity was determined with the WST-1 method.

\section{RESULTS}

All particles were spherical in shape with $60.98 \mathrm{~nm}$ in size. Cell surviving ratios without AuNPs were 96.34\% in L929, 89.68\% in DLD-1, and 76.93\% in H1299 for a single 2-Gy radiation. These ratios were $94.2 \%, 62.58 \%$, and $40.52 \%$ for L929 cells; $72.70 \%, 41.15 \%$, and $26.71 \%$ for DLD- 1 cells; and $34.72 \%$, $28.27 \%$, and $17.84 \%$ for $\mathrm{H} 1299$ cells at concentrations of $0.25 \mu \mathrm{g} / \mathrm{ml}, 0.5 \mu \mathrm{g} / \mathrm{ml}$, and $0.75 \mu \mathrm{g} / \mathrm{ml} \mathrm{AuNPs}$, respectively.

\section{CONCLUSION}

At increased concentrations, isolated unwanted cytotoxic effects of AuNPs could be observed. Radiosensitizing effect of PEI-coated AuNPs depends on cell type and AuNP concentration.

Keywords: Gold nanoparticle; megavoltage; polyethyleneimine; radiosensitization.

Copyright $\odot$ 2019, Turkish Society for Radiation Oncology

\section{Introduction}

Radiotherapy is an essential part of cancer management, and about $50 \%-60 \%$ of the patients with cancer receive radiotherapy during the treatment of their illness.[1] The healthy structures around the tumor are dose limiting in terms of acute and late toxicity. Using more precise radiation techniques such as intensity-modulated radiotherapy and applying concurrent chemotherapy and/or hyperthermia as 
a radiosensitizer (RS) are examples for enhancing intratumoral dose, and they thus improve the therapeutic ratio. $[2,3,4]$

Nanotechnology is a rapidly developing branch of science. Its use in radiation oncology has three major aspects: 1) facilitate image-guided radiotherapy (IGRT) through mechanisms based on increased uptake of particles by cancer cells similar to positron emission tomography imaging [5];2) increased synergistic cytotoxic effects with hyperthermia, chemotherapy, and targeted therapy combinations $[6,7,8,9]$; and 3 ) radiation enhancement via radiosensitizing effect.[10]

Gold nanoparticles (AuNPs) are usually various shaped with a size of $1-100 \mathrm{~nm}$ and a gold core covered by surface coating.[11] Among the elements with high $\mathrm{Z}$ number, AuNPs are the most extensively studied ones because of their relative biocompatibilityand ease in size, shape, and surface coating modifications.[4] They are small enough to pass through atypical weakly tumor vasculature so that they can extravagate and accumulate in tumor site much more easily than they do in normal tissues. This is called enhanced permeability and retention effect, and is a key characteristic of AuNPs to introduce into clinical practice. In the bloodstream, they must have sufficient circulating time without interference to the biologic effects that they are exposed to. Upon extravasation from tumor vasculature, they penetrate to the tumor interstitium and distribute homogeneously. Smaller AuNPs are advantageous in achieving more homogeneous intratumoral distribution. Uptake of cells via receptor-mediated endocytosis is dependent on size and shape, and it requires energy.[12] It is known that IR can directly or indirectly damage DNA, and has no selectivity because of the similar mass energy absorption of cancerous and healthy tissues. [13] While cytoplasmic localization of particles can yield radiosensitization, nuclear uptake enables additional DNA damage by low-energy electrons. [14,15] Yet, they must be smaller than $30 \mathrm{~nm}$ to allow uptake through the nuclear pore complex. Like most of the drugs, AuNPs are eliminated through kidney $(\leq 7 \mathrm{~nm})$ and liver $(\sim 10-100 \mathrm{~nm})$. Dedicated particles should be easily excreted by the kidneys with reduced opsonization and clearance by Kupffer cells. $[16,17,18]$

Over the past decade, the field of AuNP-based radiosensitization has undergone a tremendous growth; this fact is demonstrated by the exponential increase in the number of publications on this topic. Studies regarding AuNP-mediated radiation enhancement have been done from the early 2000s.[19,20] Most of these studies showed RS effect at superficial $\mathrm{kV}$ and less with clinically relevant MV energy levels.[21,22,23] Although there is an ongoing huge preclinical data describing the possible mechanisms behind this radiation enhancement, it is still in infancy. Interaction with matter causes a series of reactions in three phases: physical, chemical, and biological; and recent data show that AuNPs have roles in all these phases of interactions with IR. $[4,24,25]$ It would be plausible to predict that this enhancement can be affected by the modifications of IR parameters (source, energy, dose/ fraction); AuNPs (size, shape, surface coating, and functionalization); and the tumor itself such as intrinsic sensitivity, hypoxic fraction, and so on. From bench to bedside use of AuNP as an RS, the optimal concentrations of AuNPs for different types of tumors should be thoroughly examined.[10]

This study aimed to characterize the cytotoxicity on normal fibroblasts (L929), colon (DLD-1), and lung (H1299) cancer cell lines via AuNP-mediated radiation dose enhancement under MV energies.

\section{Materials and Methods}

\section{Cell Culture}

Colon (DLD-1) and lung (H-1299) cancer cells were obtained from American Type Culture Collection. All cultures were supplemented with $10 \%$ fetal bovine serum and $1 \%$ penicillin and streptomycin. Cell lines were maintained in monolayers in a tissue culture humified incubator at $37^{\circ} \mathrm{C}$ with $5 \% \mathrm{CO}_{2} / 95 \%$ air for 24 $\mathrm{h}$ and sub-cultured every 3-4 days to maintain exponential growth.

\section{AuNP Synthesis}

AuNPs coated with polyethyleneimine (PEI) and 3-aminophenyl boronic acid, which were previously synthesized for another study, were used in our work. [26] AuNPs were added and provided the same concentration of gold nanoparticles in the culture during irradiation.

\section{Irradiation Setup}

Megavoltage X-ray (6 MV) irradiations were performed using the Elekta linear accelerator. Petri dishes contain a layer of malignant cells plus about $2 \mathrm{~mm}$ of medium and $18 \mathrm{~mm}$ air. The prescribed dose was $2 \mathrm{~Gy}$, and SSD was set to $100 \mathrm{~cm}$ using a $20 \times 20 \mathrm{~cm}$ field. Six centimeters of plexyglass material (water-equivalent) was placed on top of the dish. The dose rate was 3.55 Gy/min. 
The gafchromic film was placed under the dishes to evaluate dose homogeneity and to irradiate with a single dose of $2 \mathrm{~Gy}$. After radiation exposure, the dosimetry film demonstrated that the target area was homogeneously exposed to radiation.

\section{Hematoxylin-Eosin Staining}

A $20 \times 10^{3}$ cells/well of L929, DLD-1, and H1299 cells were placed in a 48 -well plate of $10 \%$ fetal bovine serum and $1 \%$ penicillin streptomycin containing DMEM and RPMI and incubated with $5 \% \mathrm{CO}_{2}$ at $37^{\circ} \mathrm{C}$ for $24 \mathrm{~h}$. Afterwards, cells were treated with different amounts of AuNPs $(0.25 \mu \mathrm{g} / \mathrm{ml}, 0.5 \mu \mathrm{g} / \mathrm{ml}, 0.75 \mu \mathrm{g} / \mathrm{ml})$ and incubated another $24 \mathrm{~h}$ and then 2 Gy RT was applied. Alcohol was put into cells in decreasing concentrations $(100 \%, 96 \%, 80 \%, 70 \%, 50 \%)$ for 1 min for dehydration. Cell morphology was examined under the light microscope. Experiments were repeated thrice.

\section{Double Staining}

Double staining was performed to quantify the number of apoptotic and necrotic cells. The L929, DLD-1, and $\mathrm{H} 1299$ cells were placed in $10 \mathrm{ml}$ of PBS solution in a 48 -well plate $\left(20 \times 10^{3}\right.$ cells/well). Ribonuclease A inhibits cytoplasmic RNA staining, and propodium iodide stains necrotic and Hoescht 33342 stains apoptotic cells. Cells were subjected to RPMI and DMEM and incubated with $5 \% \mathrm{CO}_{2}$ at $37^{\circ} \mathrm{C}$ for $24 \mathrm{~h}$. Then three different concentrations $(0.75 \mu \mathrm{g} / \mathrm{ml}, 0.5 \mu \mathrm{g} / \mathrm{ml}$, $0.25 \mu \mathrm{g} / \mathrm{ml}$ ) of AuNPs were added and incubated for another 24-h repeated thrice. Afterwards, they were washed with PBS (after the incubation, the cells media were discarded) and stained with $70 \mu \mathrm{l}$ double staining dye for $15 \mathrm{~min}$ at dark. Cells were examined with FITC- and DAPI-filtered fluorescent inverted microscope. A 20-fold magnification was used for images.

\section{WST-1 Cytotoxicity Test}

Initially cells were plated for $24 \mathrm{~h}$, and then treated with $0.25 \mu \mathrm{g} / \mathrm{ml}, 0.50 \mu \mathrm{g} / \mathrm{ml}$, and $0.75 \mu \mathrm{g} / \mathrm{ml} 60.98 \mathrm{~nm}$ AuNPs for $24 \mathrm{~h}$. Then cells were washed; and cell media was discarded and incubated in fresh culture medium without $100 \mu \mathrm{l}$ phenol red. The cells were then exposed to $10 \mu \mathrm{l}$ WST-1 solution for $4 \mathrm{~h}$, and plates were read using a microplate reader at $440 \mathrm{~nm}$. The cell numbers in the control and AuNP-exposed samples were counted; thus, toxicity of different concentration of AuNPs was analyzed.

Following incubation, the absorbance was measured in a microplate reader at a wavelength of $440 \mathrm{~nm}$ to determine the toxicity of the gold particles alone.
In the second phase of the experiment, after $24 \mathrm{~h}$ exposure with AuNPs, cells were irradiated with 2 Gy photon beams. After irradiation, AuNP-exposed and unexposed cells (control) were incubated in culture medium for another $24 \mathrm{~h}$, and then viability was tested for the IR and IR+AuNP groups.

\section{Radiation Enhancement Ratio}

The radiation enhancement ratio (RER) is defined as the ratio of survival fractions without and with AuNPs for a specific dose that is $2 \mathrm{~Gy}$ in this setting. It has the benefit of directly comparing the biologic response caused by the nanoparticles at a specific dose level.

\section{Results}

\section{Morphologic Assessment of Cells (H\&E staining)}

Cells were examined under a light microscope after AuNP and AuNP+IR exposure, and results were presented in Figures 1, 2, 3 and Table 1. Without any exposure, all three types of cells were morphologically normal with a clear cytoplasm-nucleus boundary and placed dispersedly in the medium. After PEI-coated AuNPs exposure, cells morphology was changed according to the amount of AuNPs used.

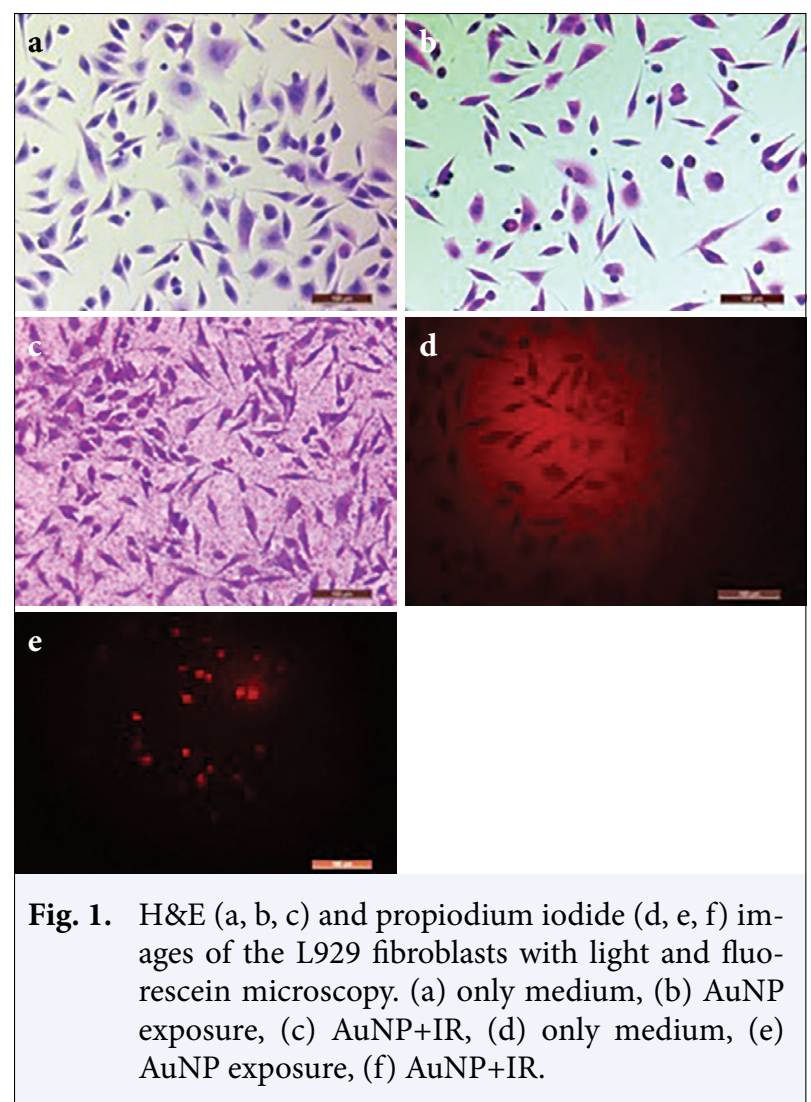


Cells were aggregated, lost their cytoplasmic membrane integrity, decreased in volume, and detached from the plate. These changes were most abundant in H1299 cells and least in fibroblasts and exacerbated with IR. Cross-linking between positively charged AuNPs with glycosaminoglycan and collagens caused intercellular organic material accumulation leading to cytoplasmic membrane damage. This may result in decreased uptake of nutrients in cancer cells and thus cell death.

\section{Double Staining of Nucleus}

The PI-stained necrotic cell ratios and microscopic images are presented in Table 2 and Figures 1, 2, 3. The ratio of necrotic cells with PI-stained nucleus was $1 \%$ -

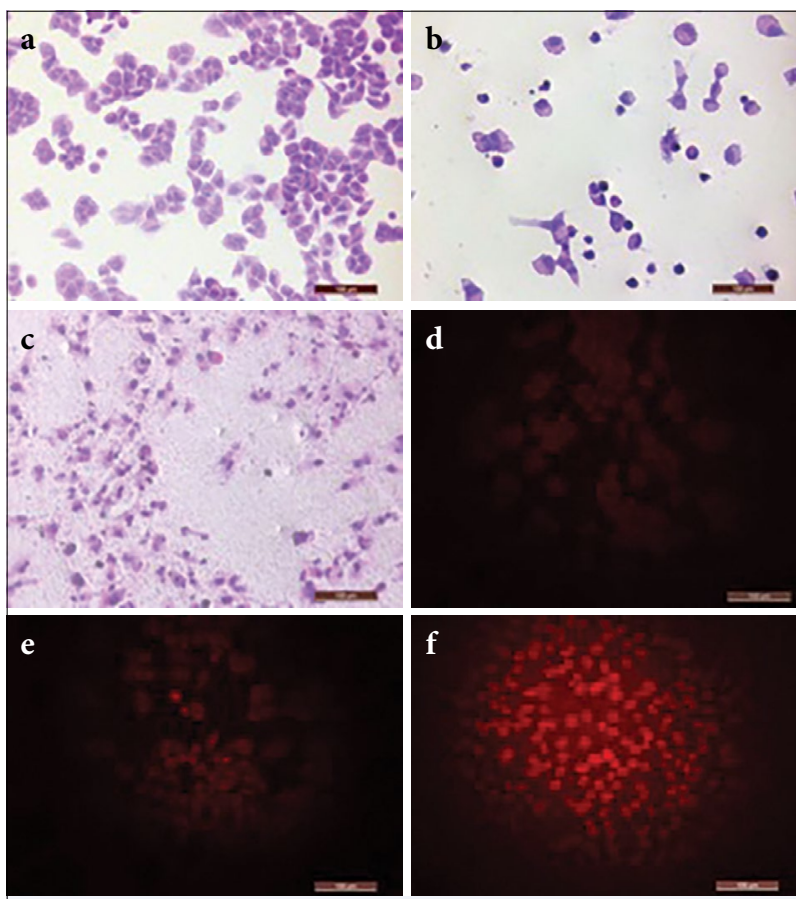

Fig. 2. $H \& E(a, b, c)$ and propiodium iodide $(d, e, f)$ images of the DLD-1 colon cancer cells with light and fluorescein microscopy. (a) only medium, (b) AuNP exposure, (c) AuNP+IR, (d) only medium, (e) AuNP exposure, (f) AuNP+IR.
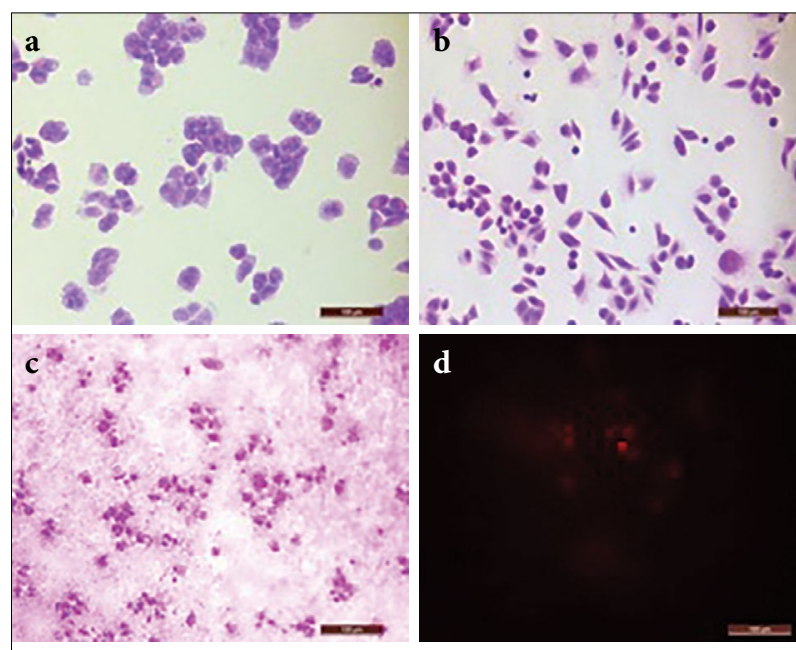

d
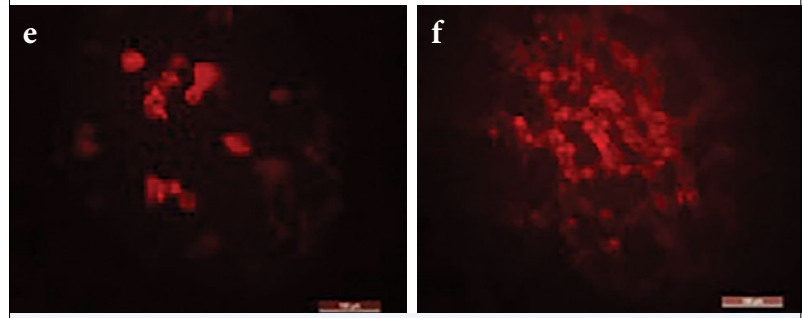

Fig. 3. $H \& E(a, b, c)$ and propiodium iodide (d, e, f) images of the H1299 lung cancer cells with light and fluorescein microscopy. (a) only medium, (b) AuNP exposure, (c) AuNP+IR, (d) only medium, (e) AuNP exposure, (f) AuNP+IR.

$4 \%$, and it increased with increasing AuNP concentrations. The nucleus was mostly intact except H1299 cells with 0.50 and $0.75 \mu \mathrm{g} / \mathrm{ml}$ AuNPs.

\section{Viability}

Cell surviving ratios without AuNPs were 96.34\% in L 929 (Fig. 1), 89.68\% in DLD-1 (Fig. 2), and 76.93\% in H1299 (Fig. 3) for a single 2-Gy radiation. These ratios were $94.2 \%, 62.58 \%$, and $40.52 \%$ for L929 cells; $84.85 \%, 78.05 \%$, and $17.84 \%$ for DLD-1 cells; $34.72 \%$, $28.27 \%$, and $17.84 \%$ for $\mathrm{H} 1299$ cells at concentrations of $0.25 \mu \mathrm{g} / \mathrm{ml}, 0.5 \mu \mathrm{g} / \mathrm{ml}, 0.75 \mu \mathrm{g} / \mathrm{ml}$ AuNPs, respectively. Viability of cells after IR exposure with and without AuNPs is represented in Tables 3 and 4.

Table 1 H\&E staining results of damaged cell (\%)

\begin{tabular}{lccccc} 
& Medium & Medium+IR & $\mathbf{0 . 2 5}$ AuNP+IR & 0.50 AuNP+IR & 0.75 AuNP+IR \\
\hline L929 & 0 & 3 & 5 & 28 & 42 \\
DLD-1 & 0 & 12 & 24 & 51 & 68 \\
H1299 & 0 & 22 & 48 & 67 & 81 \\
\hline
\end{tabular}

Abb: IR, lonizing radiation; AuNP: Gold nanoparticle. 
Table 2 PI staining results of necrotic cells (\%)

\begin{tabular}{lccccc} 
& Medium & Medium+IR & $\mathbf{0 . 2 5}$ AuNP+IR & 0.50 AuNP+IR & 0.75 AuNP+IR \\
\hline L929 & 2 & 5 & 6 & 32 & 53 \\
DLD-1 & 3 & 14 & 27 & 63 & 79 \\
H1299 & 4 & 26 & 64 & 72 & 84 \\
\hline
\end{tabular}

Abb: IR, lonizing radiation; AuNP: Gold nanoparticle.

Table 3 Cell viability ratios with and without AuNP $( \pm S D)$

\begin{tabular}{lccc} 
& $\mathbf{0 . 2 5} \boldsymbol{\mu \mathbf { g } / \mathbf { m l }}$ & $\mathbf{0 . 5 0} \boldsymbol{\mu g} / \mathbf{m l}$ & $\mathbf{0 . 7 5} \boldsymbol{\mu g} / \mathbf{m l}$ \\
\hline L929 & $104.39 \pm 0.04$ & $84.41 \pm 0.06$ & $52.90 \pm 0.00$ \\
DLD-1 & $84.85 \pm 0.01$ & $78.05 \pm 0.01$ & $47.93 \pm 0.02$ \\
H1299 & $69.40 \pm 0.00$ & $45.78 \pm 0.02$ & $38.10 \pm 0.02$
\end{tabular}

AuNP: Gold nanoparticle; SD: Standard deviation.

\section{Radiation Enhancement Ratio}

Radiation enhancement ratio (RER2Gy) for DLD-1 was 1.23 and for $\mathrm{H} 1299$ was 2.21 with $0.25 \mu \mathrm{g} / \mathrm{ml}$ concentrations of AuNPs.

\section{Discussion}

Gold has long been used in the therapeutic and diagnostic medicine because it is considered as an inert, nontoxic, biocompatible metal. It has been widely studied in current medical and biological research in nanoscale level, and many researches have been done to investigate the possible role of them in the clinical setting. $[10,27,28]$ Naked AuNPs are significantly toxic both in vitro and in vivo, and appropriate coating may lessen these detrimental effects. Surface chemistry is also an important key parameter.[9] Highly positive NPs bind to negatively charged DNA causing damage to it. Amine groups also enable specific targeting of cells, for example, drugs. [29,30]

In this study, we used $60.98 \mathrm{~nm}$ spherical AuNPs coated with cationic charged PEI and $0.25 \mu \mathrm{g} / \mathrm{ml}$ AuNPs concentration considered to be safe so that at least $69 \%$ viability observed cancerous cell lines and fi- broblast continued to proliferate. The toxic effect due to AuNPs showed a significant difference between normal and cancerous cells at low concentrations, but this difference gradually diminished with increasing concentrations. The level of toxicity was also different for different tumor types; H1299 appears to be the most vulnerable group. In a study by Coulter et al., they found that AuNP uptake was preferentially observed in tumor cells, and cytotoxicity was low, so that particle concentration causing $50 \%$ of growth inhibition in cell culture defined as IC50 for normal cells were 14 times higher than tumor cells.[13] They also showed that intracellular accumulation of gold occurs in concentration and time-dependent manner. Toxic effects of nanoparticles seen more frequently on tumor cells suggest the enhanced permeation and retention effect in vivo described by Maeda et al.[31]

Formerly, radiosensitization has mainly been attributed to physical dose enhancement occurring at kilovoltage $(\mathrm{kV})$ photon energies by means of photoelectric absorption of gold as a high $\mathrm{Z}$ material. However, data about different mechanisms of radiobiological effects regarding radiosensitization are growing [4], and experimental studies using clinically relevant MV energies showed significant dose enhancements in vitro and in vivo suggesting other possible mechanisms of biological action, for example, oxidative stress, cell cycle distribution, and DNA repair inhibition rather than physical enhancement.[32] With the same concentration, we studied the radiation enhancement effect difference in different cancer cells. In this study, $0.25 \mu \mathrm{g} /$ $\mathrm{ml}$ dose concentration of nanoparticle was found to be safer, and an RER of 1.23 and 2.21 were found for

Table 4 Cell viability ratios with and without AuNPs after 2 Gy radiation exposure $( \pm S D)$

\begin{tabular}{lccccc} 
& Only Medium & Only IR & $\mathbf{0 . 2 5} \boldsymbol{\mu g} / \mathbf{m l}+\mathbf{I R}$ & $\mathbf{0 . 5} \boldsymbol{\mu g} / \mathbf{m l +} \mathbf{I R}$ & $\mathbf{0 . 7 5} \boldsymbol{\mu g} / \mathbf{m l +} \mathbf{I R}$ \\
\hline L929 & 100 & $96.34 \pm 0.76$ & $94.26 \pm 0.02$ & $62.58 \pm 0.01$ & $40.52 \pm 0.01$ \\
DLD-1 & 100 & $89.68 \pm 0.54$ & $72.70 \pm 0.01$ & $41.15 \pm 0.01$ & $26.71 \pm 0.02$ \\
H1299 & 100 & $76.93 \pm 2.48$ & $34.72 \pm 0.00$ & $28.27 \pm 0.02$ & $17.84 \pm 0.00$ \\
\hline
\end{tabular}

Abb: IR, lonizing radiation; SD: Standard deviation. 
DLD-1 and H1299 cells, respectively. Our observation was consistent with the results of previous studies that radiation sensitization may change with different cell types. In addition, Her et al. evaluated the radiosensitization effects of polyethylene glycol-stabilized AuNPs (PEG-AuNPs) in two human triple-negative cell lines (MDA-MB-231 and MDA-MB- 436), and they found that PEG-AuNPs sensitized both cell lines to radiation, achieving dose enhancement factors of 1.26 and 1.15 , respectively.[33]

The surface coating is an important parameter to control particle stability solubility and biocompatibility.[34,35] It also enables targeting of antibodies, drugs, and radionuclides. Citrate, polyethylene glycol, and thiol are frequently used coatings. They also led to necrosis by enhanced ROS production. PEI, which is used as a coating in this study, is a cationic polymer that binds to the anionic cell membrane phospholipids and enables uptake.[36] It can be used as a gene delivery vehicle [37], a contrast agent for imaging [38,39], and a biosensor for glutamate detection.[40]

Chithrani et al. evaluated the size and shape dependence of AuNPs' uptake into mammalian cells, and observed the highest uptake and radiosensitization with approximately $50 \mathrm{~nm}$ compared to the $14 \mathrm{~nm}$ and $70 \mathrm{~nm}$.[41] They were also the first who observed relatively decreased but still significant radiosensitization at MV energies.[42] They showed that HeLa cells treated with $50 \mathrm{~nm}$ citrate-AuNPs increased the number of $\gamma-\mathrm{H} 2 \mathrm{AX}$ and 53BP1 foci at 4 and $24 \mathrm{~h}$ post-irradiation at both $220 \mathrm{kVp}$ and $6 \mathrm{MV}$ energies that were indicative of delayed DNA repair, a key mode of radiosensitization.

Wang et al. reported the radiosensitization effect of glucose-capped AuNPs with different sizes (16 nm and $49 \mathrm{~nm}$ ) on triple-negative breast cancer cells in the presence of MV energy. They showed increased RS effect with $49 \mathrm{~nm}$ AuNPs with an SER of 1.86 compared to $16 \mathrm{~nm}$ AuNPs with an SER of 1.49. Moreover, they demonstrated that the rate of the cells arrested in G2/M phase were increased with AuNPs' exposure, more with $49 \mathrm{~nm}$ AuNPs, a possible mechanism for enhanced radiation sensitization effect because $\mathrm{G} 2 / \mathrm{M}$ phase is the most radiosensitive phase of the cell cycle. [43] We found an RER of 1.23 and 2.21 for colon and lung cancer cells with similar size but different coating AuNPs. Not only particle size but shape, surface coating, concentration, and cell type may change radiation enhancement. To date, because different approaches, for example, SER, DMRX\%, REF is used to quantify NP radiation enhancement effect; it is challenging to interpret the results even with identical nanoparticles and cell type.

There are certain limitations of the study. First, although staining of cells showed us cell membrane, cytoplasm, and nuclear damage, we were not able to determine the intracellular distribution of AuNPs, in terms of uptake and localization that can affect both the isolated toxicity of AuNPs and radio sensitization. Defining the underlying mechanism for RS effect is also critical for possible further clinical application.

AuNP-related cytotoxicity was observed not only in cancerous cells but also in noncancerous fibroblasts. This toxic effect is more pronounced at increasing concentrations that can limit the use of AuNP. This study also suggests that lower concentration of AuNPs acting only on cancer cells can be used as RSs and are celltype dependent.

\section{Peer-review: Externally peer-reviewed.}

Conflict of Interest: No conflict of interest.

Financial Support: No financial support.

Authorship contributions: Concept - S.A.A., M.T.; Design - S.A.A., M.T.; Supervision - S.A.A., M.T.; Materials S.A.A., M.T.; Data collection \&/or processing - S.A.A., M.T.; Analysis and/or interpretation - S.A.A., M.T.; Literature search - S.A.A.; Writing - S.A.A.; Critical review - S.A.A.

\section{References}

1. Delaney G, Jacob S, Featherstone C, Barton M. The role of radiotherapy in cancer treatment: estimating optimal utilization from a review of evidence-based clinical guidelines. Cancer 2005;104(6):1129-37.

2. Chen AM, Yang CC, Marsano J, Liu T, Purdy JA. Intensity-modulated radiotherapy for nasopharyngeal carcinoma: improvement of the therapeutic ratio with helical tomotherapy vs segmental multileaf collimatorbased techniques. Br J Radiol 2012;85(1016):e537-43.

3. Arslan SA, Ozdemir N, Sendur MA, Eren T, Ozturk HF, Aral IP, et al. Hyperthermia and radiotherapy combination for locoregional recurrences of breast cancer: a review. Breast Cancer Management 2017;6(4):117-26.

4. Her S, Jaffray DA, Allen C. Gold nanoparticles for applications in cancer radiotherapy: Mechanisms and recent advancements. Adv Drug Deliv Rev 2017;109:84-101.

5. AlZaki A, Joh D, Cheng Z, De Barros AL, Kao G, Dorsey J, et al. Gold-loaded polymeric micelles for computed tomography-guided radiation therapy treatment and radiosensitization. ACS Nano 2014;8(1):104-12.

6. Diagaradjane P, Shetty A, Wang JC, Elliott AM, Schwartz J, Shentu S, et al. Modulation of in vivo tu- 
mor radiation response via gold nanoshell-mediated vascular-focused hyperthermia: characterizing an integrated antihypoxic and localized vascular disrupting targeting strategy. Nano Lett 2008;8:1492-500.

7. Setua S, Ouberai M, Piccirillo SG, Watts C, Welland M. Cisplatin-tethered gold nanospheres for multimodal chemo-radiotherapy of glioblastoma. Nanoscale 2014;6(18):10865-73.

8. Bonner JA, Lawrence TS. Doxorubicin decreases the repair of radiation-induced DNA damage. Int J Radiat Biol 1990;57:55-64.

9. Hainfeld JF, O'Connor MJ, Dilmanian FA, Slatkin DN, Adams DJ, Smilowitz HM. Micro-CT enables microlocalisation and quantification of Her2-targeted gold nanoparticles within tumour regions. Br J Radiol 2011;84(1002):526-33.

10. Wang AZ, Tepper JE. Nanotechnology in radiation oncology. J Clin Oncol 2014;32(26):2879-85.

11. Grzelczak M, Pérez-Juste J, Mulvaney P, Liz-Marzán LM. Shape control in gold nanoparticle synthesis. Chem Soc Rev 2008;37(9):1783-91.

12. Huo S, Ma H, Huang K, Liu J, Wei T, Jin S, et al. Superior penetration and retention behavior of $50 \mathrm{~nm}$ gold nanoparticles in tumors. Cancer Res 2013;73(1):319-30.

13. Coulter JA, Jain S, Butterworth KT, Taggart LE, Dickson GR, McMahon SJ, et al. Cell type-dependent uptake, localization, and cytotoxicity of $1.9 \mathrm{~nm}$ gold nanoparticles. Int J Nanomedicine 2012;7:2673-85.

14. Xiao F, Zheng Y, Cloutier P, He Y, Hunting D, Sanche L. On the role of low-energy electrons in the radiosensitization of DNA by gold nanoparticles. Nanotechnology 2011;22(46):465101.

15. McMahon SJ, Hyland WB, Muir MF, Coulter JA, Jain S, Butterworth KT, et al. Biological consequences of nanoscale energy deposition near irradiated heavy atomnanoparticles. Sci Rep 2011;1:18.

16. Fraga S, Brandão A, Soares ME, Morais T, Duarte JA, Pereira L, et al. Short- and long-term distribution and toxicity of gold nanoparticles in the rat after a single-dose intravenous administration. Nanomedicine 2014;10(8):1757-66.

17. Sadauskas E, Danscher G, Stoltenberg M, Vogel U, Larsen A, Wallin H. Protracted elimination of gold nanoparticles from mouse liver. Nanomedicine 2009;5(2):162-9.

18. Hwang JH, Kim SJ, Kim YH, Noh JR, Gang GT, Chung $\mathrm{BH}$, et al. Susceptibility to gold nanoparticle-induced hepatotoxicity is enhanced in a mouse model of nonalcoholic steatohepatitis. Toxicology 2012;294(1):27-35.

19. Hainfeld JF, Slatkin DN, Smilowitz HM. The use of gold nanoparticles to enhance radiotherapy in mice. Phys Med Biol 2004;49(18):N309-15.

20. Mesa AV, Norman A, Solberg TD, Demarco JJ, Smathers JB. Dose distributions using kilovoltage $\mathrm{x}$-rays and dose enhancement from iodine contrast agents. Phys Med Biol 1999;44(8):1955-68.

21. Khoshgard K, Hashemi B, Arbabi A, Rasaee MJ, Soleimani M. Radiosensitization effect of folate-conjugated gold nanoparticles on HeLa cancer cells under orthovoltage superficial radiotherapy techniques. Phys Med Biol 2014;59(9):2249-63.

22. Lin Y, McMahon SJ, Scarpelli M, Paganetti H, Schuemann J. Comparing gold nano-particle enhanced radiotherapy with protons, megavoltage photons and kilovoltage photons: a Monte Carlo simulation. Phys Med Biol 2014;59(24):7675-89.

23. Lin Y, McMahon SJ, Paganetti H, Schuemann J. Biological modeling of gold nanoparticle enhanced radiotherapy for proton therapy. Phys Med Biol 2015;60(10):4149-68.

24. Misawa M, Takahashi J. Generation of reactive oxygen species induced by gold nanoparticles under $\mathrm{x}$-ray and UVIrradiations. Nanomedicine 2011;7(5):604-14.

25. Cheng NN, Starkewolf Z, Davidson RA, Sharmah A, Lee C, Lien J, Guo T. Chemical enhancement by nanomaterials under X-ray irradiation. J Am Chem Soc 2012;134(4):1950-3.

26. ÇiftçI H, Alver E, Çelik F, Metin A, Tamer U. Non-enzymatic sensing of glucose using a glassy carbon electrode modified with gold nanoparticles coated with polyethyleneimine and 3-aminophenylboronic acid. Microchim Acta 2016;183:1479-86.

27. Zheng Y, Hunting DJ, Ayotte P, Sanche L. Radiosensitization of DNA by gold nanoparticles irradiated with high-energy electrons. Radiat Res 2008;169(1):19-27.

28. Wolfe T, Chatterjee D, Lee J, Grant JD, Bhattarai S, Tailor R, et al. Targeted gold nanoparticles enhance sensitization of prostate tumors to megavoltage radiation therapy in vivo. Nanomedicine 2015;11(5):1277-83.

29. Zheng Y, Sanche L. Gold nanoparticles enhance DNA damage induced by anti-cancer drugs and radiation. Radiat Res 2009;172(1):114-9.

30. Rathinaraj P, Lee K, Park SY, Kang IK. Targeted images of $\mathrm{KB}$ cells using folate-conjugated gold nanoparticles. Nanoscale Res Lett 2015;10:5.

31. Maeda H, Nakamura H, Fang J. The EPR effect for macromolecular drug delivery to solid tumors: Improvement of tumor uptake, lowering of systemic toxicity, and distinct tumor imaging in vivo. Adv Drug Deliv Rev 2013;65(1):71-9.

32. Schuemann J, Berbeco R, Chithrani DB, Cho SH, Kumar R, McMahon SJ, et al. Roadmap to Clinical Use of Gold Nanoparticles for Radiation Sensitization. Int J Radiat Oncol Biol Phys 2016;94(1):189-205.

33. Her S, Cui L, Bristow RG, Allen C. Dual Action Enhancement of Gold Nanoparticle Radiosensitization by Pentamidine in Triple Negative Breast Cancer. Radiat Res 2016;185(5):549-62. 
34. Kobayashi K, Wei JJ, Lida R, Ijiro K, Niikura K. Surface Engineering of Nanoparticles for Therapeutic Applications. Polym J 2014;46:460-8.

35. Kumari A, Yadav SK. Cellular interactions of therapeutically delivered nanoparticles. Expert Opin Drug Deliv 2011;8(2):141-51.

36. Godbey WT, Wu KK, Mikos AG. Poly(ethylenimine) and its role in gene delivery. J Control Release 1999;60(2-3):149-60.

37. Kichler A, Leborgne C, Coeytaux E, Danos O. Polyethylenimine-mediated gene delivery: a mechanistic study. J Gene Med 2001;3(2):135-44.

38. Zhang Y, Wen S, Zhao L, Li D, Liu C, Jiang W, et al. Ultrastable polyethyleneimine-stabilized gold nanoparticles modified with polyethylene glycol for blood pool, lymph node and tumor CT imaging. Nanoscale 2016;8(10):5567-77.

39. Luo X, Peng X, Hou J, Wu S, Shen J, Wang L. Folic acid-functionalized polyethylenimine superpara- magnetic iron oxide nanoparticles as theranostic agents for magnetic resonance imaging and PD-L1 siRNA delivery for gastric cancer. Int J Nanomedicine 2017;12:5331-5343.

40. Hamdan SK, Mohd Zain A. In vivo Electrochemical Biosensor for Brain Glutamate Detection: A Mini Review. Malays J Med Sci 2014;21:12-26.

41. Chithrani BD, Ghazani AA, Chan WC. Determining the size and shape dependence of gold nanoparticle uptake into mammalian cells. Nano Lett 2006;6(4):662-8.

42. Chithrani DB, Jelveh S, Jalali F, van Prooijen M, Allen C, Bristow RG, et al. Gold nanoparticles as radiation sensitizers in cancer therapy. Radiat Res 2010;173(6):719-28.

43. Wang C, Jiang Y, Li X, Hu L. Thioglucose-bound gold nanoparticles increase the radiosensitivity of a triplenegative breast cancer cell line (MDA-MB-231). Breast Cancer 2015;22(4):413-20. 